\title{
MEDIATING EFFECTS OF SELF-EFFICACY ON FRUIT AND VEGETABLE CONSUMPTION AMONG NURSING AND MIDWIFERY STAFF IN ARDABIL- APPLICATION OF TRANSTHEORETICAL MODEL
}

\author{
Mehdi Khezeli', Sajjad Narimani², Nategh Abbasgholizadeh ${ }^{3}$, Hadi Darvishi ${ }^{4}$
}

1PhD, Department of Health Education and Health Promotion, School of Health, Kermanshah University of Medical Sciences, Kermanshah, Iran.

2Instructor, Faculty of Nursing and Midwifery, Social Determinants of Health Research Center, Ardabil University of Medical Sciences, Ardabil, Iran.

${ }^{3}$ Assistant Professor of Health Education, Department of Public Health, School of Public Health, Ardabil University of Medical Sciences, Ardabil, Iran.

${ }^{4}$ M. Sc., Health Network of Gilan-e Gharb, Kermanshah University of Medical Sciences, Kermanshah, Iran.

\section{BACKGROUND}

\section{ABSTRACT}

It is highly recommended to promptly assess motivation and readiness to change in individuals who wish to achieve significant lifestyle behaviour changes in order to improve their health. In particular, motivation should be assessed in those who face the difficulty in behavioural changes.

This study is aimed to investigate the mediating effects of self-efficacy on the relationships between predicting variables and outcome variable using the Transtheoretical Model.

\section{MATERIALS AND METHODS}

This cross-sectional study was conducted with the participation of 300 nursing and midwifery staffs employed in hospitals of Ardabil city, which were selected by systematic random sampling method. The data gathering tool was a Transtheoretical Model scale. Validity and reliability was confirmed in previous study. The data were analysed by SPSS 19 using the descriptive statistics, Spearman correlation test and Multiple Logistic Regression Analysis.

\section{RESULTS}

In total, $41.34 \%$ of the samples had normal BMI. The majority of subjects (77.3\%) were in the early stages of change for fruit and vegetable consumption and only 22.7 percent were located in active stages. Regression revealed that self-efficacy was the strongest predictor of stage of change $(\beta=0.357, \mathrm{P}=0.001)$ and mediated the relationships of behavioural processes with stages of change $(\beta=0.369, \mathrm{P}=0.001)$.

\section{CONCLUSION}

This study showed a strong correlation between self-efficacy, decisional balance and processes of change with stages of change. So, we suggest that in order to promoting the fruit and vegetable consumption, these variables be considered as the basis of the interventional program. Also considering the mediating effect of self-efficacy as the strongest predictor, we suggest a targeted and appropriate application of this variable in the interventions.

\section{KEYWORDS}

Self-Efficacy, Fruit and Vegetable, Transtheoretical Model.

HOW TO CITE THIS ARTICLE: Khezeli M, Narimani S, Abbasgholizadeh N, et al. Mediating effects of self-efficacy on fruit and vegetable consumption among nursing and midwifery staff in Ardabil- application of transtheoretical model. J. Evolution Med. Dent. Sci. 2018;7(17):2125-2128, DOI: 10.14260/jemds/2018/475

\section{BACKGROUND}

Chronic diseases associated with nutrition such as obesity, cardiovascular disease, type 2 diabetes and stroke have endangered the health of people around the world. $(1,2)$ The effects of nutrition-related diseases, beyond the effects on health have brought a significant financial burden on the population, which has been accompanied by a progressive increase in health costs. $(3,4)$ This financial burden is not only caused by the economic problems of society, but also caused

'Financial or Other Competing Interest': None.

Submission 13-03-2018, Peer Review 06-04-2018,

Acceptance 12-04-2018, Published 23-04-2018.

Corresponding Author:

Sajjad Narimani,

Faculty of Nursing and Midwifery,

Social Determinants of Health Research Center,

Ardabil University of Medical Sciences, Ardabil, Iran.

E-mail: s.narimani@arums.ac.ir

DOI: $10.14260 /$ jemds $/ 2018 / 475$

\section{(c) (i) $\$$}

by some employees who are absent from work due to chronic illness and disrupt the production cycle and the provision of services.(5) On the other hand, an unhealthy diet is known as one of the risk factors for nutrition related chronic disorders.(2) Nutritional interventions such as reducing the consumption of saturated oils and fast foods and increasing the fruits and vegetables consumption are the most costeffective interventions that can reduce the burden of chronic diseases. ${ }^{(1-3)}$

The Educational Hospitals are the environments in which the personnel are ready to eat unhealthy or fast foods due to their high workload and lack of adequate time, which can have negative effects on health of both the individual and the patient.(6) Given that health providers spent more than twothirds of their time at these centres, these centres can be one of the targeted centres for educational planning.(7,8) Due to the use of health education models, behavioural change has been a priority for health care providers. Transtheoretical 
model is one of the most common model in health education profession for changing the unhealthy behaviours.

The Transtheoretical Model (TTM) of behaviour change is an integrated theory that assesses an individual's readiness to act on a new healthy behaviour and provides strategies or processes of change to guide the individual toward the health. This model is composed of constructs including stages of change, processes of change, self-efficacy and decisional balance. The TTM suggests that individuals move through five stages of change: pre-contemplation, contemplation, preparation, action and maintenance. For each stage of change, different intervention strategies are needed to move to the next stage. The stages of change generally included the following: Contemplation stage in which people intend to change their behaviour over the next six months; Preparation stage in which individuals intend to take action in the next month; Action stage in which people have created specific and clear changes in their lifestyle in the past 6 months; and Maintenance stage in which people have created specific and obvious changes in their behaviour over six months. $(9,10)$

Self-efficacy refers to the confidence level of people in finishing work behaviour based on the skills they have mastered.(11) In general, self-efficacy influences on work stress, job burnout and work satisfaction in clinical nurses. $(12,13)$ Stages of change model in dietary intervention program has been focused on the assessment of dietary behaviours and stages of change. Less attention has been paid to the investigation of mediating effect of other TTM constructs on stages of transition. The purpose of this study was to explore relationships between TTM variables and to examine the mediating effects of self-efficacy on the relationships between predictor variables (Decisional balance and processes of change) and the outcome variable (Stages of change).

\section{MATERIALS AND METHODS}

This cross-sectional study was conducted with participation of 300 nursing and midwifery staff from educational hospitals of Ardabil, Iran. For selecting people to participate in research, we mixed the Quota sampling and systematic random sampling methods. First, based on the total research sample, the quota of sample for each hospital was determined from the total sample. Then according to the full list of the nurses and midwifes employed in five educational hospitals, the individuals were selected according to proportional number by systematic random sampling method. In this study, we met the ethical issues including freedom and discretion to participate in research, confidentiality of information and explanation of the objectives of study for the participants at the beginning of the research. Also, the informed consent form was obtained from all participants. The data were analysed by SPSS 19 using the descriptive statistics, Spearman correlation test and multiple logistic regression analysis, in which $\mathrm{p}<0.05$ was considered as a significant level.

The instruments used in the study included stage of change algorithm and the questionnaire for measuring the processes of change (Cognitive, behavioural), decisional balance (pros, cons) and self-efficacy. The stage of change algorithm consists of two questions with four subscales to determine the five stages of the behavioural change in the consumption of fruits and vegetables.(14) Each question was measured with five ordinal questions that were scored on a 5-point Likert scale ranging from 1 (Strongly disagree) to 5 (Strongly agree). Each question asked whether staff were in the precontemplation, contemplation, preparation, action or maintenance stage. The validity of this scale was confirmed by the expert panel method and its reliability was confirmed by a two-week test-retest with a correlation of 0.87 in previous study.(14) Based on the options of this scale at the precontemplation stage, samples do not pay attention to consume five servings of fruits and vegetables in a day. At the contemplation stage, subjects think about taking fruits and vegetables five servings in a day for the next six months. At preparation stage, subjects think about taking five servings of fruits and vegetables daily for the next 30 days. At action stage, subjects eat fruits and vegetables five servings per day for the six months. At the maintenance stage, subjects consume fruits and vegetables at regular five servings for more than six months. (9)

The Processes of Change scale determine two group processes (Cognitive or Behavioural) across the stages of change of fruits and vegetables consumption and includes 20 questions. Of these, ten questions are related to the cognitive process including consciousness raising, dramatic relief, environmental re-evaluation, self-re-evaluation and social liberation. Also, ten questions are related to behavioural processes including self-liberation, counter conditioning, helping relationships, reinforcement management and stimulus control. Two questions provided for each process in the 5-state Likert scale from "never" equal(1) to "always" equal.(5) In the study of Khezeli et al, panel of experts approved Content Validity Index (CVI) and Content Validity Ratio (CVR) of items. In addition, the internal consistency of process of changing questions using Cronbach's Alpha has been reported as 0.73.(15)

To measure individual self-efficacy in fruits and vegetables consumption 5 questions were considered, which were assessed on a 5-point scale with a total score of 5 to 25 . Validity of questions was confirmed by panel expert and correlation coefficient of scale with Cronbach's alpha of 0.84 .

In the scale of decisional balance, two important sub-scale was measured including perceived benefits and perceived barriers. For each of these subscales, five questions were included in the questionnaire, in which results of subtraction of these two subscale showed the decision balance. Participants were asked to rate the questions using a 5-point Likert scale including "it is not important at all,"(1) to "extremely important."(5) The internal coefficient of questions was calculated with Cronbach's alpha, which was 0.70 for perceived benefits and 0.74 for perceived barriers.

Descriptive statistics were used to describe the participant's general characteristics. The correlation analysis was used to determine the relationships between variables. Multiple logistic regression to examine the mediating effects of self-efficacy in the stages of change model in the following three situations: (1) The regression of the mediating effects of self-efficacy on predictive variables (Behavioural processes and decisional balance); (2) The regression of the effects of dependent variable (Stages of change) on predictor variables (Behavioural processes and decisional balance); and (3) The regression of effects of the dependent variable (Stages of change) on mediator (Self-efficacy) and predictor variables (Behavioural processes and decisional balance). 


\section{RESULTS}

The descriptive analysis showed that 218 (73\%) of the samples were married and $124(41.34 \%)$ of the subjects had a natural body index. 259 (86.34\%) were undergraduate and 17 (5.7\%) graduate students. A third of the participants in the study also worked in the intensive care unit and operating room. Considering the structure of the stages of change in the of Transtheoretical model 118 (39.3\%) were in the precontemplation stage, $60(20 \%)$ at the contemplation stage, $54(18 \%)$ at the preparation stage, $18(6 \%)$ in the action stage and $50(16.7 \%)$ were in the maintenance stage.

\section{Correlation between Process of Change, Decisional Balance and Self-Efficacy}

The results of correlation analysis showed that cognitive processes of change, self-efficacy and consensus views of the decisional balance (Cons) were strongly correlated with the structure of the stages of change $(p<0.01)$. The cognitive processes were related to decisional balance and self-efficacy structures. Also, self-efficacy according to our hypothesis had a high correlation with all structures of the Transtheoretical Model (Table 1).

\section{Multiple Logistic Regression Analysis of Self-Efficacy Mediation Effects}

Multiple regression analysis was conducted to determine the mediating effects of self-efficacy in the relationship of the process of change with stages of change and also decisional balance with the stages of change (Chart 1 and 2) and results showed that the process of change is not a suitable predictor for the stages change stage $(\beta=.052, p=.115)$, but due to the mediating effects of it can affect the stages of change $(\beta=369$, $\mathrm{p}=0.001)$. Also, the decisional balance that had a significant correlation with the stages of change $(\beta=-248, p=0.001)$ had a double effect on the stages of change with the mediating effect of self-efficacy $(\beta=-0.419, p=0.001)$.

\begin{tabular}{|c|c|c|c|c|c|c|}
\hline \multicolumn{2}{|c|}{ Variables } & $\begin{array}{c}\text { Stages of } \\
\text { Change }\end{array}$ & $\begin{array}{l}\text { Cognitive } \\
\text { Processes }\end{array}$ & $\begin{array}{c}\text { Behavioural } \\
\text { Processes }\end{array}$ & $\begin{array}{c}\text { Perceived } \\
\text { Benefits }\end{array}$ & $\begin{array}{c}\text { Perceived } \\
\text { Barriers }\end{array}$ \\
\hline \multirow{2}{*}{ Process of Change } & Cognitive & $.168^{\text {粠 }}$ & & & & \\
\hline & Behavioural & .080 & .732 *** & & & \\
\hline \multirow{2}{*}{ Decisional Balance } & Perceived benefits & $.138^{*}$ & $.507^{\text {粪粠 }}$ & 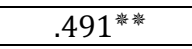 & & \\
\hline & Perceived barriers & $-.178^{\text {䅈粠 }}$ & 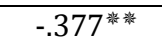 & $-.310^{\text {絭粠 }}$ & $-.662^{\text {米粠 }}$ & \\
\hline Self-Efficacy & & $.352^{\text {䄅敞 }}$ & $.176^{\text {絭敞 }}$ & $.295^{\text {䄅粠 }}$ & $.175^{\text {粠粠 }}$ & $-.330^{\text {煞㓥 }}$ \\
\hline
\end{tabular}

$\left({ }^{* *}\right)$ represents a significant level of 0.01 and $\left({ }^{*}\right)$ indicates a significant level of 0.05 .

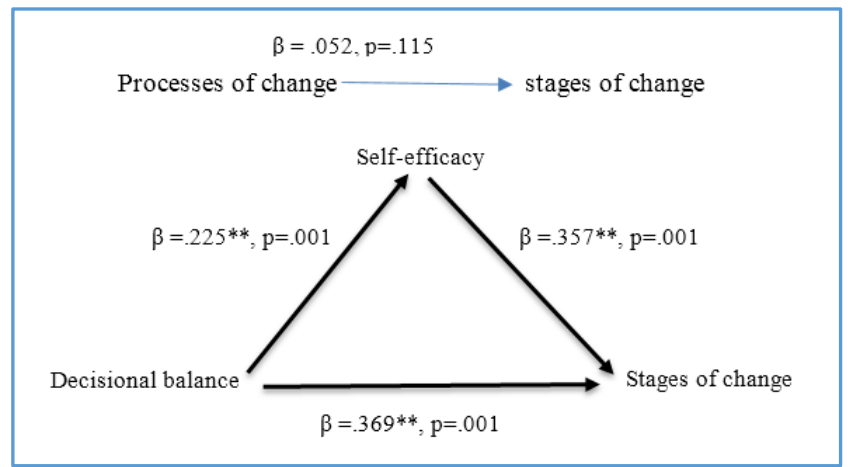

Figure 1. Mediating Effects of Self-Efficacy on Relationship between Processes of Change and Stages of Change

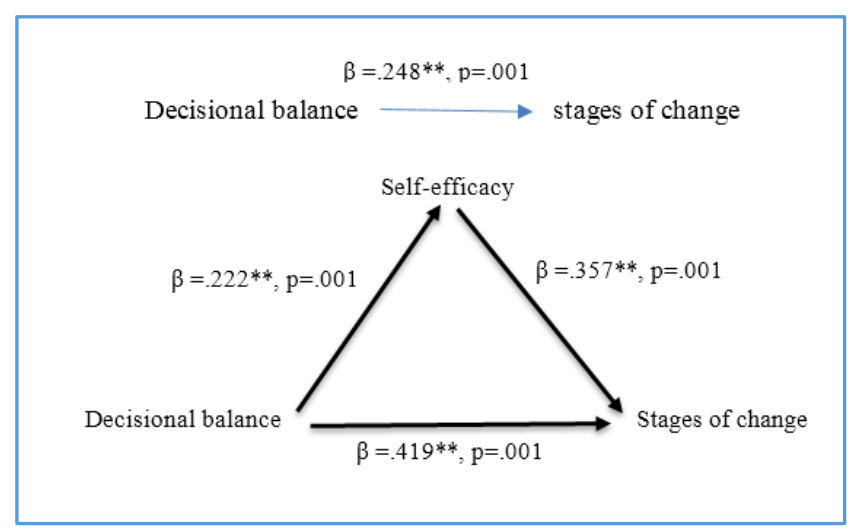

Figure 2. Mediating Effects of Self-Efficacy on the Relationship between Decisional Balance and Stages of Change

\section{DISCUSSION}

The results of this study showed that self-efficacy was the strongest predictor of consumption of fruits and vegetables among nursing and midwifery staff and then decisional balance was considered as another effective predictor. A similar study among students showed that self-efficacy was an appropriate predictor and mediator for improving the consumption of fruits and vegetables, which was consistent with the present study.(16) Another study in students showed that self-efficacy was considered as the strongest predictor of consumption of fruits and vegetables, which was in line with the study.(17) In another study that was conducted in Bandar Abbas among high school students consistent with the present study, the decisional balance (Perceived benefits and perceived barriers) and self-efficacy were the strong predictors of the stages of change for consumption of fruits and vegetables.(18) Contrary to the Noia and Prochaska study, in which the decisional balance were the most influential variables to promote fruit and vegetable consumption among African-American youth(19) in our study, self-efficacy was the strongest mediator of promoting fruit and vegetable consumption among nursing and midwifery staffs. In the study of Horwath et al, the self-liberation was introduced as the strongest structure for change, which was inconsistent with the present study.(20)In most studies, the results suggested the use of sound health education and health promotion models for changing and adopting behaviours by individuals. $(20,21)$ Therefore, in order to promote any behaviour in different groups and societies, these groups should be studied and their stages of change should be determined. Then depending on the stages of change, the processes of change, decisional balance and self-efficacy of 
the subjects, the appropriate measures should be done to promote the effectiveness of the actions.

Given the self-reporting for data gathering in the present study using the questionnaires, there is the possibility of desirability and bias due to the nature of the tool. Therefore, we suggest that in subsequent studies, other information gathering methods should be used in conjunction with the questionnaire to reduce the possibility of bias.

\section{CONCLUSION}

This study showed a strong correlation between self-efficacy, decisional balance and processes of change with stages of change and the mediating effects of self-efficacy on the relationship of other structures on improving the stages of change for consumption of fruits and vegetables. Considering these relationships, we suggest that in order to increase the amount of fruit and vegetable consumption in the nursing and midwifery staff of Ardabil Educational Centers, selfefficacy and cognitive processes should be considered as the basis of the program. Future studies should attempt to identify variables that strengthen the relationship between attitude-behaviour for different types of behaviours in order to provide clues for effective intervention strategies. Also, in the regression relationships between the structures of the transtheoretical model with the stages of change respectively, self-efficacy, perceived barriers and cognitive processes were significant predictors that could be considered in order to make more effective interventions for increasing the consumption of fruits and vegetables.

\section{ACKNOWLEDGEMENT}

We would like to thank the senior managers of the educational centres of Ardabil for their sincere cooperation in this research.

\section{REFERENCES}

[1] Beaglehole R, Bonita R, Alleyne G, et al. UN high-level meeting on non-communicable diseases: addressing four questions. Lancet 2011;378(9789):449-55.

[2] WHO. Global action plan for the prevention and control of non-communicable disease 2013-2020. World Health Organization, 2013. http://www.who.int/nmh/publications/ncd-actionplan/en/. Accessed 23 Feb 2016

[3] Bloom D, Cafiero ET, Jané-Llopis E, et al. The global economic burden of non-communicable diseases. Geneva: World Economic Forum, 2011. http:// www3.weforum.org/docs/WEF_Harvard_HE_ GlobalEconomicBurdenNonCommunicableDiseases_2 011.pdf. Accessed 22 Feb 2016.

[4] Chaker L, Falla A, van der Lee SJ, et al. The global impact of non-communicable diseases on macroeconomic productivity: a systematic review. Eur J Epidemiol 2015;30(5):357-95.

[5] Fitzgerald S, Kirby A, Murphy A, et al. A cost-analysis of complex workplace nutrition education and environmental dietary modification interventions. BMC Public Health 2017;17(49).

[6] NICE. Behavior change: the principles for effective interventions. National Institute for Health and Care Excellence. 2007. https://www.nice.org.uk/ guidance/ph6. Accessed 21 Feb 2016
[7] Signal LN, Walton MD, Ni Mhurchu C, et al. Tackling 'wicked' health promotion problems: a New Zealand case study. Health Promot Int 2013;28(1):84-94.

[8] Capacci S, Mazzocchi M, Shankar B, et al. Policies to promote healthy eating in Europe: a structured review of policies and their effectiveness. Nutr Rev 2012;70(3):188-200.

[9] Prochaska JO, Redding CA, Evers KE. Transtheoretical Model and Stages of change. In: Glanz K, Rimer KB, Viswanath K, eds. Health behavior and health education: theory, research and practice. 4 th edn. San Francisco: Jossey-Bass 2008.

[10] Prochaska JO, Johnson S, Lee P. The transtheoretical model of behavior change. In: Shumaker SA, Ockene JK, Riekert KA, eds. The handbook of health behavior change. New York: Springer Publishing Company 2009: p. 59-83.

[11] Conner M. Self-efficacy, stress and social support in retention of student registered nurse anesthetists. AANA J 2015;83(2):133-8.

[12] Bong YS, So HS, You HS. A study on the relationship between job stress, self-efficacy and job satisfaction in nurses. J Korean Academy of Nursing Administration 2011;15(3):425-33.

[13] Pang J, Du H, Wu SX. Improve the effectiveness of job burnout of nurses' sense of self-efficacy on reducing analysis. J Nurs Sci 2013;38(5):271-5.

[14] Khezeli M, Ramezankhani A, Bakhtiyari M. Effect of education on nutritional knowledge and stages of fruit and vegetable consumption in elders based on stages of change model. J Mazand Univ Med Sci 2012;22(91):90-100.

[15] Khezeli M, Ramezankhani A, Aghaei A, et al. Processes of change associated with the fruits and vegetables consumption across stages of change in women: application of transtheoretical model. JEMDS 2017;6(87):5991-6.

[16] Kreausukon P, Gellert P, Lippke S, et al. Planning and self-efficacy can increase fruit and vegetable consumption: a randomized controlled trial. J Behav Med 2012;35(4):443-51.

[17] Pearson N, Ball K, Crawford D. Predictors of changes in adolescents' consumption of fruits, vegetables and energy-dense snacks. The British Journal of Nutrition 2011;105(5):795-803.

[18] Davoodi SH, Hosseini Z, Aghamolaei T, et al. Fruit and vegetable consumption in high school students in Bandar Abbas, Iran: an application of the transtheoretical model. Archives Iran Med 2017;20(6):3449.

[19] Di Noia J, Prochaska JO. Mediating variables in a transtheoretical model dietary intervention program. Health Education and Behavior 2010;37(5):753-62.

[20] Horwath CC, Schembre SM, Motl RW, et al. Does the transtheoretical model of behavior change provide a useful basis for interventions to promote fruit and vegetable consumption? American Journal of Health Promotion 2013;27(6):351-7.

[21] Hussein RAEH. Can knowledge alone predict vegetable and fruit consumption among adolescents? A transtheoretical model perspective. J of the Egyptian Public Health Association 2011;86(5-6):95-103. 